University of Wollongong

Research Online

Faculty of Business - Papers (Archive)

Faculty of Business and Law

$1-1-2014$

Cross-region and cross-sector asset allocation with regimes

Paul Dou

Macquarie University

David R. Gallagher

Macquarie Graduate School of Management

David Schneider

UniSuper Management Limited

Terry S. Walter

University of Technology Sydney, twalter@uow.edu.au

Follow this and additional works at: https://ro.uow.edu.au/buspapers

Part of the Business Commons

Research Online is the open access institutional repository for the University of Wollongong. For further information contact the UOW Library: research-pubs@uow.edu.au 


\title{
Cross-region and cross-sector asset allocation with regimes
}

\begin{abstract}
Cross-region and cross-sector asset allocation decisions are one of the most fundamental issues in international equity portfolio management. Equity returns exhibit higher volatilities and correlations, and lower expected returns, in bear markets compared to bull markets. However, static mean-variance analysis fails to capture this salient feature of equity returns. We accommodate the nonlinearity of returns using a regime switching model across both regions and sectors. The regime-dependent asset allocation potentially adds value to the traditional static mean-variance allocation. In addition, optimal allocation across sectors provide greater benefits compared to international diversification, which is characterized by higher returns, lower risks, lower correlations with the world market and a higher Sharpe ratio.
\end{abstract}

\section{Disciplines}

Business

\section{Publication Details}

Dou, P. Y., Gallagher, D. R., Schneider, D. \& Walter, T. S. (2014). Cross-region and cross-sector asset allocation with regimes. Accounting and Finance, 54 (3), 809-846. 


\title{
Cross-Region, Cross-Sector Asset Allocation with Regimes
}

\author{
Paul Dou ${ }^{\mathrm{a}, \mathrm{b}}$, David R. Gallagher ${ }^{\mathrm{a}, \mathrm{b}}$, David Schneider ${ }^{\mathrm{c}}$, Terry S. Walter ${ }^{\mathrm{d}}$ \\ ${ }^{a}$ Macquarie Graduate School of Management, Sydney \\ ${ }^{b}$ Capital Markets CRC Limited, Sydney \\ ${ }^{c}$ UniSuper Management Limited, Melbourne \\ ${ }^{d}$ Discipline of Finance, UTS Business School, University of Technology, Sydney
}

Corresponding author: David R. Gallagher

Telephone: + 61298509975

Fax: +61298509942

Postal address: MGSM, Macquarie University, North Ryde NSW 2109 Australia

\begin{abstract}
Cross-region and cross-sector asset allocation decisions are one of the most fundamental issues in international equity portfolio management. Equity returns exhibit higher volatilities and correlations, and lower expected returns, in bear markets compared to bull markets. However, static mean-variance analysis fails to capture this salient feature of equity returns. We accommodate the non-linearity of returns using a regime switching model across both regions and sectors. The regime-dependent asset allocation adds value to the traditional static mean-variance allocation. In addition, optimal allocation across sectors provides benefits compared to international diversification, in particular higher returns, lower risks, lower correlation with the world market and a higher Sharpe ratio.
\end{abstract}

Keywords: asset allocation, sector rotation, regime switching, Markov switching

JEL Classifications: C13, C22, E30, G11, G23 


\title{
Cross-Region, Cross-Sector Asset Allocation with Regimes
}

\begin{abstract}
Cross-region and cross-sector asset allocation decisions are one of the most fundamental issues in international equity portfolio management. Equity returns exhibit higher volatilities and correlations, and lower expected returns, in bear markets compared to bull markets. However, static mean-variance analysis fails to capture this salient feature of equity returns. We accommodate the non-linearity of returns using a regime switching model across both regions and sectors. The regime-dependent asset allocation adds value to the traditional static mean-variance allocation. In addition, optimal allocation across sectors provides benefits compared to international diversification, in particular higher returns, lower risks, lower correlation with the world market and a higher Sharpe ratio.
\end{abstract}

Keywords: asset allocation, sector rotation, regime switching, Markov switching

JEL Classifications: C13, C22, E30, G11, G23 


\section{Introduction}

For international equity fund managers, the asset allocation decision - how much to invest in each major region and sector - is a key determinant of their portfolio performance. Region and sector weights are usually determined on the basis of a model that characterizes the joint distribution of equity returns. Most studies assume that equity returns are generated by a stationary process with mean, variances and covariances of returns that are constant over time. However, there is growing empirical evidence that equity returns follow a more complicated process with multiple 'regimes', namely different market or economic conditions, each of which is associated with a very different distribution of returns (e.g. Ang and Bekaert, 2002a, 2002b, 2004; Garcia and Perron, 1996 and Guidolin and Timmermann, 2007). This empirical feature of equity returns highlights the need for a dynamic asset allocation model that accounts for different distributions of asset returns in different regimes.

Our paper investigates whether a dynamic asset allocation that accounts for regimes can allocate assets more efficiently across regions and sectors (i.e., generate higher returns for investors) than a static Markowitz' (1952) mean-variance analysis. Similar to Hamilton's (1989) regime switching model, we define regimes as unobservable to investors, who can only infer regime probabilities from past return observations. We consider two regimes where the first (second) regime has the characteristics of a bull (bear) market with high (low) returns and low (high) volatilities. These two regimes offer very different investment opportunities so investors' asset allocations vary significantly over time as they revise their beliefs about the underlying regime probabilities.

We demonstrate that a regime-dependent asset allocation that holds different mean-variance efficient portfolios in different regimes can outperform the static mean-variance optimal portfolio in both cross-region and cross-sector. Most evidently, sector allocations provide higher diversification benefits and perform better than optimal allocation across regions in both in-sample (1995 2002) and out-of-sample (2003 2010).

Our study is most closely related to Ang and Bekaert (2004), who document how the presence of regimes can be incorporated into two asset allocation programs - a global asset allocation setting with six equity markets and a market timing setting for U.S. cash, bonds and equity. Ang and Bekaert (2004) find that regime switching strategies have the potential to outperform the static mean-variance analysis because they are able to capture different distributions of asset returns at different times in the business cycle. However, they indicate 
that the superior performance of regime switching strategies may be linked to a specific historical period, in their case 1975 to 2000 . Using the same MSCI country dataset in a different period (1995 to 2010), we find that the regime dependent portfolio only marginally outperforms the static strategy in the out-of-sample period (2003 2010).

We contribute to the asset allocation literature by demonstrating how the presence of regimes is exploitable in a sector allocation program. Previous research investigating the merits of specific sector rotation strategies is surprisingly scarce, given that the industry level allocation is a fundamental component of most portfolio constructions. Conventional market wisdom also posits that different sectors perform differently in various stages of the business cycle (or financial conditions). The focus of previous sector rotation studies has been on selecting appropriate indicators that can identify when the portfolio should be shifted to a more defensive or aggressive position (e.g. Sassetti and Tani, 2006). However, techniques used in these studies are often heuristic rather than scientific in nature and lack theoretical justification. ${ }^{1}$ Our paper addresses these issues using a regime switching model that derives the regime shift indicators statistically from the stock returns data and volatilities in different regimes, hence allowing investors to strategically invest in the optimal defensive (aggressive) portfolio in bear (bull) markets.

The empirical results for our regime switching sector rotation strategy are economically important. In our out-of-sample analysis (2003 to 2010), the regime-dependent sector allocation delivers an average annual return of $13.13 \%$ (Sharpe ratio $=0.93$ ), compared to the annual returns on a static mean-variance sector allocation and the world market portfolio of $7.31 \%($ Sharpe ratio $=0.48)$ and $7.03 \%($ Sharpe ratio $=0.30)$ respectively.

Our paper also contributes to the ongoing debate of whether international diversification is more important and beneficial than allocation across sectors. Earlier researchers find that international diversification matters more than diversification across sectors (e.g. Solnik, 1974 and Griffin and Karolyi, 1998). However, more recent studies document that industry factors have grown in importance in recent years (e.g. Baca et al., 2000 and Cavaglia et al., 2000). Most of these earlier studies use factor approaches and do not directly consider the optimal asset allocation implications. Our optimal asset allocation results indicate that industry diversification yields higher performance in the sample period examined. We document that during the period from 1995 to 2010, cross-sector optimal allocation generates

\footnotetext{
${ }^{1}$ See section 2 for detailed discussion.
} 
higher returns, lower risk, lower correlations with the world market, and higher Sharpe ratios than cross-region optimal allocation. In addition, a regime dependent sector allocation outperforms the regime dependent regional allocation in both in-sample and out-of-sample periods.

The paper is organized as follows. Section 2 discusses the previous literature and section 3 describes our data. Section 4 documents the regime switching model and the model estimation. Section 5 illustrates the asset allocation methodology and compares the performance of regime-dependent portfolios against the static mean-variance optimal portfolios. Section 6 concludes the paper.

\section{Literature}

\subsection{Regime switching and asset allocation}

Regime switching is firstly used in Hamilton (1989) to model switches between periods of high and low GNP growth. In a regime shifting framework, the transition from one regime to another follows a Markov chain. That is, at each point in time, there is a certain probability that the process will stay in the same regime, or transition to another regime in the next period. These transitional probabilities might be constant or they might depend on other variables. Since Hamilton (1989)'s seminal work, a large literature has developed to apply regime switching models to financial time series variables. Turner et al. (1989) is the first paper in the finance literature that uses a regime switching model to find high and low stock returns and variances in different time periods. Ang and Bekaert (2002b, 2002c), Bekaert, Hodrick and Marshall (2001), Garcia and Perron (1996) and Gray (1996) find strong evidence of regimes in U.S. and international short-term interest rate data. Ang and Bekaert (2002a, 2002b), Ang and Chen (2002), Guidolin and Timmermann (2007), Perez-Quiros and Timmermann (2000) and Whitelaw (2000) all report evidence of regimes in stock or bond returns.

In the asset allocation literature, Ang and Bekaert (2002a), Ang and Bekaert (2004) and Guidolin and Timmermann (2007) consider the asset allocation implications of regime switching models, because they capture many of the properties of asset returns that emerge from the empirical studies such as having regimes with very different means, volatilities or correlations across assets. Ang and Bekaert (2002a) use a two-state model to evaluate the claim that the home bias observed in holdings of international assets can be explained by 
return correlations that increase in bear markets. Guidolin and Timmermann (2007) use a four regime model that has a crash state capturing large negative returns and a bull state capturing large positive returns. They claim that a four regime model best captures the joint distribution of stock and bond returns. Regime switching models are also useful in capturing fat tails and skewness in the distribution of asset returns (Guidolin and Timmermann (2008)).

In light of these papers, we consider a two-state Markov switching mean-variance model close in spirit to Ang and Bekaert (2004). They conclude that the presence of regimes with different correlations and expected returns is exploitable within an international equity allocation framework. In addition to examining Ang and Bekaert's (2004) cross-country asset allocation using a different sample period, our paper contributes the asset allocation literature by also investigating the regime-dependent cross-sector allocation, motivated by the recent literature that discusses the increasing importance of sector diversification.

\subsection{Cross-region, cross-sector allocation}

The risk reduction benefits of international diversification of equity portfolios have been accepted for a long time among academics (e.g., Solnik (1974)). However knowing what factors drive the co-movement in stock returns internationally has long challenged both academics and professional portfolio managers. A number of studies (e.g., Grinold et al., 1989; Heston and Rouwenhorst, 1994) examine the relative importance of country and industry factors in explaining the cross section of expected returns and establish country factors as the major influence on equity returns. Heston and Rouwenhorst (1994) decompose stock return volatility into pure country and industry sources of variation and clearly document the dominance of country-specific effects. Griffin and Karolyi (1998) find that when emerging markets are included in the sample, the proportion of portfolio variance explained by the time-series variation in pure country effects is higher than previously documented, which again indicates investors would be better off in terms of risk reduction if they pursued a geographic diversification strategy rather than an industry one.

The relative importance of the country factor has been challenged, however, by Baca et al. (2000), Cavaglia et al. (2000), Cavaglia and Moroz (2002) and Chen et al. (2006). These studies conclude that the importance of sector factors has grown to exceed that of country factors in both developed and emerging markets in recent years. They attribute these empirical findings to an increased level of international capital markets integration, which blurs national borders and hence diminishes the significance of country effects. However, 
Brooks and Del Negro (2004) argue that the rise in industry effects is simply a temporary phenomenon associated with the information technology bubble, rather than a reflection of greater economic integration across countries. Ferreira and Gama (2004) document that, in the 1990s, correlations among local industries have declined and there is a greater penalty for not being well diversified across industries.

On balance, the studies suggest that industry factors have become as important as, if not more than, country factors. Nevertheless, most of the studies discussed above do not consider the optimal asset allocation implications of the growing importance of sector effects. As the financial markets become increasingly integrated, it makes intuitive sense to ask whether sector asset allocation could add benefits to the widely practiced international asset allocation.

A relatively unexplored area of sector asset allocation is with regard to sector rotation strategies. Most professional investors seem to agree that sector rotation strategies can be extremely profitable with good market timing skills (e.g., Stovall, 1996). However, academic research has not yet rigorously tested whether investors can profit from sector rotation strategies. The major obstacle has been to select appropriate and timely indicators that identify the exact jumps or turning points of business cycles or financial conditions. Sorensen and Burke (1986) use relative strength analysis for 43 industries and find that an industry momentum-based rotation strategy produces abnormal profits. Using macroeconomic variables such as the default premium, maturity premium, and aggregate dividend yield, Beller et al. (1998) create an industry trading strategy that earned economically significant profits. Sassetti and Tani (2006) find that the sector rotation strategy is profitable using a number of technical indicators including relative strength and moving averages. Conover et al. $(2005,2008)$ find that cyclical stocks prosper during expansive monetary policy periods (while a restrictive environment favours defensive stocks) and a sector rotation strategy based on the monetary policy produces excess returns.

Most of these studies implicitly assume that market timing is driven by exogenous variables. Therefore the success of sector rotation strategies relies solely on the appropriate choice of exogenous indicators. However, using exogenous indicators suffers from reverse causation or omitted variables problems. Hence such strategies could imperfectly capture the true underlying dynamics of time-varying sector performances. To address these potential problems, we propose a Markov switching process that endogenously derives the turning points or jumps of regime cycles from the statistical features of stock returns, and therefore is 
not afflicted by reverse causation or omitted variables problems. As discussed in section 2.2, there is mounting evidence that suggests the Markov switching process can capture the timevarying distributions of stock returns.

\section{Data}

In the cross-region asset allocation, we focus on a group of developed equity markets that constitute the MSCI world index for an U.S. based institutional investor. We classify these developed equity markets into six regions, namely North-America, U.K. , Japan, large European countries, small European countries and the Pacific ex-Japan. ${ }^{2}$ Table 1 details all countries involved. Following Ang and Bekaert (2004), we obtain all country data from the MSCI. Our sample period is January 1995 through to March 2010.

In the cross-sector allocation investigation, we focus on 10 broad sectors classified by the MSCI Global Industry Classification Standard (GICS), namely Energy, Materials, Industrials, Consumer Discretionary, Consumer Staples, Healthcare, Financials, Information Technology (IT), Telecommunications and Utilities. All sector data come from the MSCI and the sample period is also January 1995 to March $2010 .{ }^{3}$ Stocks contained in these sector portfolios are the same stocks contained in the country portfolios.

Table 2 and 3 report some characteristics of the regional and sectoral returns data. We measure all returns in U.S. dollars. These return properties are expected to play a large role in determining mean-variance based asset allocations. For example, it is immediately apparent that the use of historical data may lead to relatively small weights to Japan, because it has witnessed relatively low returns (underperform the world market by $0.50 \%$ per month) in the past 15 years with relatively high volatility (5.61\% monthly). Similarly, a simple meanvariance optimization may lead to some large weights to small European economies, as they have relatively higher returns (outperform the world market by $0.42 \%$ per month) with moderate level of volatility (5.31\% monthly). It is also interesting to note that the IT sector has the highest mean return during the sample period, although this sector has experienced a major boom and bust.

\footnotetext{
${ }^{2}$ Our region classification is consistent with Ang and Bekaert (2004). In particular, they split the European countries into large and small markets, primarily because the small European markets may represent a diversified portfolio of economic exposures.

${ }^{3}$ We do not examine data prior to 1995 because different sector classification methods are used by MSCI.
} 


\section{Regime-Switching Model}

\subsection{Description of the model}

To maintain the parsimony of the model, we adopt Ang and Bekaert's (2004) approach, which assumes that there is only one world regime, which drives all other regions/sectors. Weakening this assumption by estimating specific regimes in each region/sector separately makes the number of parameters infeasible for estimation. The equation for the world equity return, in excess of the U.S. T-bill rate is:

$y_{t}^{w}=\mu_{s_{t}}^{w}+\sigma_{s_{t}}^{w} \varepsilon_{t}^{w}$

Here $\mu_{s_{t}}^{w}$ denotes the conditional mean (expected returns) and $\sigma_{s_{t}}^{w}$ denotes the conditional variance (volatility). We assume the world excess equity returns have two unobserved regimes, regime $i$ and $j$. This number of states may be restrictive, but including more regimes poses extreme computational problems. Two states should capture the main effects of higher order moments in equity returns. Therefore $\mu_{s_{t}}^{w}$ and $\sigma_{s_{t}}^{w}$ can take different values depending on the realization of the regime variable $s_{t}$.

The regimes $s_{t}$ follow a two-state Markov chain with a transitional matrix:

$$
\left(\begin{array}{cc}
P & 1-P \\
1-Q & Q
\end{array}\right)
$$

which can be characterized by two transitional probabilities:

$P=p\left(s_{t}=i \mid s_{t-1}=i\right)$

$Q=p\left(s_{t}=j \mid s_{t-1}=j\right)$

If investors know the regime, the expected excess return and volatility for the world market in the next period will be either:

$$
\begin{aligned}
& e_{i}^{w}=P \mu_{s_{t+1}=i}^{w}+(1-P) \mu_{s_{t+1}=j}^{w}, \\
& \Sigma_{i}^{w}=P\left(\sigma_{s_{t+1}=i}^{w}\right)^{2}+(1-P)\left(\sigma_{s_{t+1}=j}^{w}\right)^{2}+P(1-P)\left[\mu_{s_{t+1}=j}^{w}-\mu_{s_{t+1}=i}^{w}\right]^{2},
\end{aligned}
$$

when the regime realization today is $s_{t}=i$, or

$e_{j}^{w}=(1-Q) \mu_{s_{t+1}=i}^{w}+Q \mu_{s_{t+1}=j}^{w}$ 
$\Sigma_{j}^{w}=(1-Q)\left(\sigma_{s_{t+1}=i}^{w}\right)^{2}+Q\left(\sigma_{s_{t+1}=j}^{w}\right)^{2}+Q(1-Q)\left[\mu_{s_{t+1}=j}^{w}-\mu_{s_{t+1}=i}^{w}\right]^{2}$,

when the regime realization today is $s_{t}=j$.

The first component in equations (4) and (6) is a weighted average of the conditional variances in the two regimes; the second component is a jump component that arises because the conditional mean is different across regimes.

In contrast to Ang and Bekaert (2004), which does not allow regime switching in idiosyncratic region/sector behaviour, we model the individual region/sector excess returns $y_{t}^{v}$, using a regime switching CAPM model:

$y_{t}^{v}=\mu_{s_{t}}^{v}+\beta_{s_{t}}^{v} \mu_{s_{t}}^{w}+\beta_{s_{t}}^{v} \sigma_{s_{t}}^{w} \varepsilon_{t+1}^{w}+\bar{\sigma}_{s_{t}}^{v} \varepsilon_{t+1}^{v}$

Where $\beta_{s_{t}}^{v}$ denotes different correlations between the individual region/sector excess returns and the world excess equity returns in different regimes, $\mu_{s t}^{v}$ denotes alphas in regime one and regime two, and $\bar{\sigma}_{s t}^{v}$ denotes the regime-dependent region/sector's idiosyncratic volatility. With regime switches, this model captures time-variation in expected returns, volatilities and correlations, all driven by the world regime variable.

Ang and Bekaert (2004) state that accommodating regime switching alphas, regime switching betas, and/or regime switching idiosyncratic volatilities fit the data better, yet some estimations do not behave well in their model, and it is often difficult to make inferences about the regime in such models. To avoid this possible over-parameterisation problem, we do not allow regional and sector returns to affect the regime realization process and hence only estimate equation (7) after regime probabilities are inferred from the world return process. Regime probabilities play a critical role in the estimation of regime switching models, which uses maximum likelihood techniques.

We follow Hamilton (1989)'s maximum likelihood estimation algorithms to estimate the parameters in equation (1) to (6) and regime probability, which is the probability that tomorrow's regime is a particular regime given current and past information $\tau_{t}$, that is, the world equity returns data $\check{y}_{T}=\left(y_{t}^{w} y_{t-1}^{w} \ldots y_{1}^{w} y_{0}^{w}\right)$. Because the regimes are unobservable, their effects and incidence must be inferred from the data. Maximizing the likelihood function that accounts for all possible regime sequences is the most direct manner to accomplish this task. Let the parameters of the likelihood to be $\theta$, the likelihood function is: 
$f\left(\check{y}_{T} ; \theta\right)=\prod_{t=1}^{T}\left(\sum_{i=1}^{2} f\left(y_{t} \mid \tau_{t-1}, S_{t}=i ; \theta\right) p\left(S_{t}=i \mid \tau_{t-1} ; \theta\right)\right)$

\subsection{Model Estimation}

To reliably estimate the model parameters, we need to use a reasonably long period of time. We split the total 15 year sample period into the first eight years (the in-sample period) and the last seven years (the out-of-sample period) ${ }^{4}$. The in-sample period, which runs from January 1995 to December 2002, is used to estimate the parameters of the regime switching model. The out-of-sample period spans January 2003 to March 2010. Table 4 contains the estimation results for the region model in equations (1)-(7), using in-sample data only. The first regime is a bull market, where world excess returns are expected to yield $0.98 \%$, with $2.26 \%$ volatility per month. On the other hand, the second regime, a bear market, has a negative mean world excess return ( $-0.14 \%$ per month) and higher volatility (4.92\% per month). The negative expected return in the bear market regime may seem extreme and appears to be incompatible with equilibrium arguments by which risky assets should earn a positive risk premium. However, because we have a relatively short sample period (eight years), it is not unreasonable to expect equity returns to be lower than the risk-free return in the bear market, particularly when the estimation period contains a major market downturn (burst of the tech bubble). The transitional probabilities P and Q are 0.98 and 0.97 respectively, which indicate that, over the sample period, the probability of going into a bull (bear) market next month is $98 \%$ (97\%), conditional on the current regime being a bull (bear) market.

The expected durations of these two regimes are 40 and 29 months, respectively. ${ }^{5}$ Regional betas are estimated with a high level of statistical significance in both regimes, and their magnitudes seem economically sensible. Betas for each region increase in the bear regime, apart from Japan, which has a beta of 1.68 during the normal period but lower systematic risk (beta $=1.10)$ in the bear market. With the rather low average returns during the sample period, it is surprising that Japan has the highest beta in both regimes. Nevertheless, the large negative alpha ( $-0.35 \%$ per month) would result a much lower expected return for Japan during bear markets. The alpha parameters are not significantly different from zero for all regions, except the small European economies in the bull market (1.05\% per month, $\mathrm{t}=3.00$ ). Note that alphas for North America and Small European countries are highest $(0.12 \%$ and

\footnotetext{
${ }^{4}$ Each sample period would also contain a bull market and a major market down turn, namely the Dot-Com Bubble for the in sample period and the global financial crisis for the out of sample period.

${ }^{5}$ The expected duration of a regime can be calculated as $1 /(1-\mathrm{P})$, where $\mathrm{P}$ is the transitional probability.
} 
$0.18 \%$ per month) in bear markets, making equities in these regions more attractive in the bad times. Similar to the world return process, idiosyncratic volatilities for each region are lower in regime one and higher in regime two. Japan and Pacific ex-Japan exhibit the highest idiosyncratic volatilities in both regimes whereas the lowest idiosyncratic volatilities are found in North America, followed by small European economies.

The estimation procedure also yields the regime probabilities, which infers the prevailing regime in each month. We need to estimate the regime probabilities for both the in-sample (1995 to 2002) and out-of-sample period (2003 to 2010) for performance evaluation purposes. Figure 1 shows the ex ante (filtered) and ex post (smoothed) regime probabilities. The ex ante probability $p\left(s_{t}=1 \mid I_{t-1}\right)$ is the probability that the regime next month is the bull market regime given past and current information $I$ up to time $t$, the smoothed probability $p\left(s_{t}=\right.$ $\left.1 \mid I_{T}\right)$ is the probability that the regime next month is the bull market regime given all of the information $I$ present in the sample period T, i.e., from January 1995 to March 2010. To avoid hindsight bias, the filtered probability in the out of sample period from January 2003 to March 2010 is re-estimated every month. The dotted line represents two economic contraction periods during the sample period identified by the National Bureau of Economic Research (NBER) ${ }^{6}$. The financial bear markets identified by the regime-switching algorithms coincide with these economic contraction periods, namely the 2000 Dot-Com Bubble and the Global Financial Crisis.

Table 5 contains the estimation results for the sector model in equations (1)-(7). Compared to the bull regime, all sectors are less correlated with the world market in the bear regime except IT (beta $=1.89$ ) and Telecommunications (beta $=1.15$ ), primarily because the only bear regime in the estimation period is the Dot-Com Bubble, where the influence of IT and Telecommunications sectors on the world return process increased dramatically. Consumer Staples, Healthcare and Utilities, commonly recognized as defensive sectors, have rather low correlations with the world market during bad times with betas equal to $0.42,0.48$ and 0.40 respectively. Alphas are lower in the bear regime for most of the sectors. IT has the highest alpha of $0.75 \%$ per month in the bear regime, though this is not significantly different to zero. Moreover, IT has the highest volatility among all sectors in both regimes, which the model fits through a high beta and a high idiosyncratic volatility (the highest idiosyncratic volatility

\footnotetext{
${ }^{6}$ Business cycle dates identified by NBER can be found at http://www.nber.org/cycles/cyclesmain.html.
} 
of all sectors). As expected, idiosyncratic volatilities are higher in the bear regime for all sectors.

\section{Asset Allocation and Performance Results}

\subsection{Asset Allocation}

To derive the expected returns and covariance matrix for the returns on regions/sectors, we let the vector of excess returns of six regions and ten sectors, conditional on today's regime, be denoted by $e_{i}=e_{S_{t}=i}$ (with $i$ denoting the current regime), and let variance covariance matrices be denoted by $\Sigma_{i}=\Sigma_{s_{t}=i}$.

Since the mean of the world excess return switches between regimes, the expected excess return of region/sector $v$ is given by $\mu_{i}^{v}+\beta_{i}^{v} e_{i}^{w}$ for the current regime $i$, where $e_{i}^{w}$ are given in equation (3) and (5). Let $\mu_{i}$ and $\beta_{i}$ be

$$
\mu_{i}=\left(\begin{array}{c}
\mu_{i}^{1} \\
: \\
\vdots \\
\mu_{i}^{N}
\end{array}\right), \quad \beta_{i}=\left(\begin{array}{c}
\beta_{i}^{1} \\
\vdots \\
: \\
\beta_{i}^{N}
\end{array}\right)
$$

vectors for the $\mathrm{N}$ regions/sectors. Hence the expected return vector is given by:

$e_{i}=\mu_{i}+\beta_{i} e_{i}^{w}$

Therefore, expected returns differ across individual regions/sectors through their different betas and alphas with respect to the world market.

The variance covariance matrix has three components. First, there is an idiosyncratic part that we capture in a matrix $v_{i}$ for the current regime $i$, where $v_{i}$ is a matrix of zeros with $\left(\bar{\sigma}_{i}^{v}\right)^{2}$ along the diagonal. Second, the differences in systematic risk across the different regions/sectors and the correlations are driven by the variance of the world market and the betas as in a typical factor model. Because the world market variance and the betas next period depend on the realization of the regime, we have two possible variance matrices for the unexpected returns next period:

$\Omega_{i}=\left(\beta_{i} \beta_{i}^{\prime}\right)\left(\sigma_{i}^{w}\right)^{2}+v_{i}$ 
Third, the actual covariance matrix today takes into account the regime structure, in that it depends on the realization of the current regime and it adds a jump component to the conditional variance matrix, which arises because the conditional means change from one regime to the other. As a consequence, the conditional covariance matrices can be written as:

$$
\begin{aligned}
& \Sigma_{1}=P \Omega_{1}+(1-P) \Omega_{2}+P(1-P)\left(e_{1}-e_{2}\right)\left(e_{1}-e_{2}\right)^{\prime} \\
& \Sigma_{2}=(1-Q) \Omega_{1}+Q \Omega_{2}+Q(1-Q)\left(e_{1}-e_{2}\right)\left(e_{1}-e_{2}\right)^{\prime}
\end{aligned}
$$

where the subscripts indicate the current regime.

To implement mean-variance optimization, we also need to make an assumption about the risk-free rate. We assume the risk-free rate to be the 1-month T-bill rate. Hence the risk-free rate and the tangency portfolio for each month will vary over time. One obvious extension discussed in Ang and Bekaert (2004) is to impose constraints on asset allocations. This is because (i) mean-variance portfolios, based on historical data, may be quite unbalanced (see Black and Litterman, 1992), and (ii) in practice institutional investors have an intelligence overlay rather than just applying weights based on the straight model outputs. We choose to impose a short sell constraint, and a benchmark constraint that keeps asset allocations close to their market capitalization weights in the MSCI world index. The short constraint requires weights to be positive, whereas the benchmark constraint does not allow the optimal regional or sector weights to deviate from their MSCI average weights by more than $10 \%$.

Panel A and B of Table 6 show the regime-dependent expected excess returns, covariances and correlations for the regional allocation at January 2003, estimated using data from 1995 to 2002. The expected excess returns are lower for all regions in the bear regime, with Japan in particular generating a negative expected excess return (-5.75\% per annum). In line with the results of Ang and Bekaert (2002a) and Longin and Solnik (2001), our results also indicate that international equity returns are more highly correlated with each other in bear markets than in bull markets. For instance, most of cross country correlations are less than 0.5 in the bull markets and almost all correlations become greater than 0.5 in the bear markets. The average correlation increases from 0.43 to 0.57 .

Panel C of Table 6 shows the tangency portfolios weights in both regimes and static meanvariance optimization at an interest rate of $4.55 \%$, the in-sample average. When no constraints are imposed, in the bull regime, the portfolio under-weights North America, Japan, large European countries and Pacific ex-Japan relative to their average MSCI world index 
weights over the sample period. The high volatility of Japan and Pacific ex-Japan markets is the main reason. Our model also slightly over-estimates the correlation between North America and small European countries returns relative to the data, which may explain the underweight in North America. Both U.K. and small European economies are over-weighted. In the bear regime, investors switch towards the markets with less volatility and higher expected returns, namely, North America and small European countries. Although North America gets assigned a weight of $88 \%$, it does not mean the portfolio is now home biased because the investors also invest heavily small European countries $(75 \%)$.

The ability to invest heavily in the less volatile markets comes from a large short position on Japan, 53\%. However, it is probably unrealistic to implement this short position in practice. The optimal portfolio under the static mean-variance analysis sits in between the two regimedependent portfolios, but under-weights all regions relative to their MSCI world index weights except U.K. and small European countries. The optimal portfolios weights in both regime switching and static analyses do not change qualitatively under the short constraint and the benchmark constraint. All portfolios still underweight Japan and overweight small European countries. Note that under the benchmark constraint, regime-dependent and static portfolios have exactly the same allocation on Japan and small European countries (12\% and $17 \%$ respectively). The benefits of the regime switching allocation therefore only come from investors tilting towards North America and U.K. and moving away from large European countries and Pacific ex-Japan during the bear markets.

Panel A and B of Table 7 show the regime-dependent expected excess returns, covariances and correlations for the sector allocation at January 2003. Energy, Healthcare and IT show the highest expected excess returns in both regimes, whereas Materials, Industrials, Telecommunications and Utilities are clearly the losers. Unlike correlations between regions, sector correlations do not increase universally in bad times. For instance, the correlation between Consumer Staples and Telecommunications fall from 0.56 in regime one to 0.21 in regime two. Out of 45 correlation pairs, 12 pairs have decreased correlations in the bear markets, mainly concentrated within Consumer Staples, IT, Healthcare, and Telecommunications sectors. The average cross sector correlation has only increased from 0.48 to 0.52 . This feature of sector allocation provides good reason as to why diversification across sectors is important not only in good times but also in bad times. 
Panel $\mathrm{C}$ of Table 7 shows the tangency portfolios weights in both regimes and static meanvariance optimization at an interest rate of $4.55 \%$. With no constraints enforced, the portfolio in bull markets over-weights Energy, Industrials, Consumer Staples, Healthcare and Utilities relative to their average MSCI world index weights over the sample period, but underweights Materials, Consumer Discretionary, Financials, IT and Telecommunications. The high volatility is still the main problem, although IT yields the highest expected returns. In regime two, the portfolio borrows money from massively shorting Materials (-40\%), Industrials (-117\%) and telecommunications (-49\%) and invests heavily in a few sectors including Energy (73\%), Consumer Staples (58\%), Healthcare (84\%) and IT (66\%). The large short position on Industrials primarily comes from its high correlation with Consumer Discretionary and IT sectors $(0.88$ and 0.73$)$. This large short position is perhaps neither feasible nor sensible to implement in a practical asset allocation program. This issue can be addressed when constraints are imposed. The static mean-variance optimal portfolio also favours Energy, Consumer Staples, Healthcare and IT and is highly averse to Industrials and Telecommunications. When short-selling is not allowed, both regime-dependent and static optimal portfolios only invest in Energy, Consumer Staples, Healthcare and IT. The benchmark constraint is so restrictive that the regime-dependent portfolios only deviate from the static optimal portfolio marginally. More aggressive investors can obviously modify the constraint to be less restrictive but we will not demonstrate other restrictions in our simulation.

\subsection{Performance of Regime Switching Asset Allocation}

To evaluate whether regime switching asset allocation adds value to standard mean-variance optimization, we simulate a time-series of returns generated from a regime switching strategy that switches between holding two regime-dependent optimal portfolios and compare it to the returns generated from holding a static mean-variance efficient portfolio. We estimate the returns of these two strategies both in-sample and out-of-sample, with an assumed \$1 starting investment. In-sample simulation assumes the investor knows the parameters estimated from the estimation period (January 1995 to December 2002) and starts trading in January 1995. In the out-of-sample analysis, the regime-dependent and static mean-variance weights are computed using all information available up to the estimation date. The model is re-estimated every month during the out-of-sample period (January 2003 to March 2010). The regime strategy also requires the realization of regime in each month, which can be inferred from the ex-ante regime probability $\mathrm{p}\left(\mathrm{s}_{\mathrm{t}}=1 \mid \mathrm{I}_{\mathrm{t}-1}\right)$. We follow Ang and Bekaert (2004) in defining the 
regimes. When the ex-ante regime probability is larger than 0.5 , the investor classifies the regime as 1 , otherwise the regime is 2 . The performance criterion is the ex-post Sharpe ratio realized by the various strategies.

Panel A of Table 8 shows the in-sample average returns, standard deviations and Sharpe ratios realized by the static mean-variance, regime-dependent strategies and the MSCI world index for asset allocation across regions, when various constraints are considered. Compared to the world market portfolio and the static strategy, the regime-dependent strategy has higher return volatilities, compensated by higher average returns under no constraint and short constraint scenarios. The regime switching strategy has the highest ex-post Sharpe ratio when no constraint and short constraint are used, but fails to out-perform when the benchmark constraint is imposed, possibly because the benchmark constraint is so restrictive that the benefit of overweighting small European countries and underweighting Japan is largely removed. The non-constrained regime-dependent strategy does particularly well (the Sharpe ratio almost doubles that of the static strategy) because over this sample period the U.S. and small European markets generate very large returns and Japan performs very poorly. The reason for the under-performance of the world market portfolio is the presence of a relatively large Japanese equity allocation in the world market.

It is perhaps more important to examine the out-of-sample performance because no hindsight bias is introduced into the simulated returns of both strategies. Panel B of Table 8 shows, over the out-of-sample period and with no constraints, the regime-dependent strategy's average return is $8.94 \%$, higher than the average return of the static portfolio $(7.63 \%)$ and the return of the world market portfolio (7.03\%). The regime-switching portfolio's average Sharpe ratio is 0.36 , only slightly higher than the static optimal portfolio Sharpe ratio $(0.33)$, where the world market portfolio produces a Sharpe ratio of 0.30 . Note that under the short constraint and the benchmark constraint, the regime-dependent strategy delivers a higher Sharpe ratio in the out-of-sample period, compared to the world market portfolio and the static portfolio, although the out-performance is not economically significant.

Figure 2 shows how wealth accumulates over time in these strategies with no constraints. Panel A shows the out-performance of the regime-dependent strategy is particularly striking in the first five years of the in-sample period, whereas Panel B shows that the regime switching portfolio does not perform very differently during the out-of-sample period. This is probably because the cross country equity returns become more co-integrated in this period. 
The performance of the regime dependent portfolio and static optimal portfolio for the sector allocation is presented in Table 9. For the in-sample analysis, the static optimal portfolio realizes slightly lower returns, but does so at substantially lower risk than the regime dependent sector allocations. Hence the regime dependent portfolio leads to a lower insample Sharpe ratio than the static optimal portfolio. The under-performance is expected because the regime probabilities might be estimated imprecisely in the earlier trading period due to the limited data availability for estimation. With more data becoming available, the regime switching model is able to estimate the regime probability with higher precision.

Panel B shows the portfolio performance in the out-of-sample period, from January 2003 to March 2010. With no constraints imposed, the regime dependent strategy delivers a sizable $13.13 \%$ average annual return (11.74\% annualized volatility) in a relatively bearish period, where the static portfolio and the world market portfolio generate an average return of only $7.31 \%$ and $7.03 \%$ (with $10.65 \%$ and $15.87 \%$ annualized volatility), respectively. The regime switching portfolio's Sharpe ratio is 0.93 , almost double the Sharpe ratio of the static strategy (0.48). The regime dependent portfolio consistently out-performs the world market and the static optimal portfolio when the short constraint and the benchmark constraint are imposed. The extremely successful performance of the regime dependent strategy comes from the ability of the model to correctly identify the defensive sectors, such as Energy, Consumer Staples and Healthcare, which hedge against high volatilities and low returns so well in the bear regime.

Figure 3 presents results for wealth accumulated over the in-sample and out-sample period under no constraint scenario. Panel A shows that the regime dependent strategy yields lower returns than the static portfolio during the first three years of the in-sample period, probably due to an imprecise classification of regimes. In Panel B, it is interesting to note that, particularly over the second half of the out-of-sample period, wealth accumulated from the regime dependent strategy is almost unaffected while the world market is deeply in turmoil. Unlike the regional allocation, even the static mean-variance sector allocation produces a defensive portfolio that is more or less decoupled from the world market portfolio in the bear regime.

It is worthwhile to compare the performance of static and regime switching asset allocation across regions and across sectors. Table 10 shows the average returns, standard deviations, betas and Sharpe ratios generated by the static and the regime dependent strategies for region 
and sector allocations for each year from 1995 to 2009. On average, cross-sector allocation provides higher returns, lower risks, lower betas and higher Sharpe ratios than cross-region allocation. In the cross-region allocation program, the regime-dependent portfolio produces a higher Sharpe ratio (0.59 in-sample and 0.36 out-of-sample), together with a higher beta (1.07 in-sample and 1.11 out-of-sample) than the static strategy. The regime switching strategy out-performs the static strategy in Sharpe ratio in ten out of the total 15 years, including the bear market from 2000 to 2002. In the cross-sector allocation, the regimedependent strategy produces a higher Sharpe ratio (0.93), however a lower beta $(0.34)$ than the static strategy out of sample. The regime switching strategy in sector allocation outperforms the static strategy in 12 out of 15 years. Most remarkably, the regime switching sector allocation yields an average return of only $-0.86 \%$ per month and a monthly volatility of $5.65 \%$, compared to the world market average monthly return of $-4.21 \%$ and volatility of $6.81 \%$ in year 2008 , the largest stock market decline in a single year since the Great Depression.

\section{Conclusion}

Static mean-variance asset allocation fails to exploit the characteristics of high volatility and low equity returns in bad times. Although in high-volatility environments regional returns tend to be more correlated collectively, this is not the case for sector returns. Thus diversification across sectors should provide additional benefits. This salient feature of regional and sector returns should not be ignored by active portfolio managers.

While it is not our objective to develop the best asset allocation program, we demonstrate how the regime switching model could match the non-linear feature of returns and improve the performance of asset allocation across regions and sectors. However, as with any sample the observed out-performance could be sample-period specific. In addition, the performance has not taken into account of market frictions such as transaction costs and taxes.

Nevertheless, the regime switching strategy should be robust to transaction costs because the probability of staying within the same regime is relatively high and portfolio turnover is low.

Two main conclusions can be drawn from our results. First, both regional and sector regime dependent portfolios out-perform the regional and sector static mean-variance portfolios, albeit the outperformance of the regime dependent region allocation is trivial. In particular, the regime dependent sector allocation delivers the best performance, because the portfolio 
heavily invests in defensive sectors that have low correlations and hence provides considerable diversification benefits in bear markets. Second, cross-sector optimal allocation performs better on average than cross-region optimal allocation.

The performance of the regime switching strategy could possibly be improved by incorporating the following extensions. First, we only consider a two regime structure in our study. Further research can look at the implications for the performance of cross-region and cross-sector allocations using three or four regime structures, which might fit equity returns data better (Guidolin and Timmermann, 2007).

Second, because we only use monthly returns data, it would be interesting to examine regime switching behaviour on a weekly basis, which might signal more timely information, especially during the start of the bear markets when immediate diversification is needed the most, although using weekly data might create more frequent switches between regimes and generate much higher portfolio turnover and trading costs.

Finally, this study adopts an International CAPM model where beta is the single factor that characterizes expected returns. Another viable alternative is to infer the regimes and formulate expected returns from factor models such as macroeconomic variables that can influence stock returns (e.g. the inflation rate, see Fama and Schwert, 1977; Jaffe and Mandelker, 1976; Nelson, 1977). A regime switching allocation that trades based on macroeconomic and stock characteristic regimes might offer additional benefits.

\section{Acknowledgements}

The authors gratefully acknowledge the research funding and support provided by UniSuper. We are indebted to seminar participants at UniSuper, Quantitative Group and Monash University Symposium, Australasian Finance and Banking Conference and Hong Kong Polytechnic University, and the comments of Adrian Pagan, John Pearce, Adam Merrington, Dennis Sams, David Tan, Sirimon Treepongkaruna, and Cameron Truong which improved the paper substantially. All remaining errors are authors' responsibility.

\section{References}

Ang, A., Bekaert, G., 2002a. International asset allocation with regime shifts. Review of Financial Studies 15, 1137-1187. 
Ang, A., Bekaert, G., 2002b. Regime switches in interest rates. Journal of Business \& Economic Statistics 20, 163-182.

Ang, A., Bekaert, G., 2002c. Short rate nonlinearities and regime switches. Journal of Economic Dynamics and Control 26, 1243-1274.

Ang, A., Bekaert, G., 2004. How regimes affect asset allocation. Financial Analysts Journal 60, 86-99.

Ang, A., Chen, J., 2002. Asymmetric correlations of equity portfolios. Journal of Financial Economics 63, 443-494.

Baca, S.P., Garbe, B.L., Weiss, R.A., 2000. The rise of sector effects in major equity markets. Financial Analysts Journal 56, 34-40.

Bekaert, G., Hodrick, R.J., Marshall, D.A., 2001. Peso problem explanations for term structure anomalies. Journal of Monetary Economics 48, 241-270.

Beller, K.R., Kling, J.L., Levinson, M.J., 1998. Are industry stock returns predictable? Financial Analysts Journal 54, 42-57.

Black, F., Litterman, R., 1992. Global portfolio optimization. Financial Analysts Journal 48, 28-43.

Brennan, M.J., Schwartz, E.S., Lagnado, R., 1997. Strategic asset allocation. Journal of Economic Dynamics and Control 21, 1377-1403.

Brooks, R., Catao, L., 2000. The new economy and global stock returns. Working Paper, International Monetary Fund.

Brooks, R., Del Negro, M., 2004. The rise in comovement across national stock markets: market integration or IT bubble? Journal of Empirical Finance 11, 659-680.

Cavaglia, S., Brightman, C., Aked, M., 2000. The increasing importance of industry factors. Financial Analysts Journal 56, 41-54.

Cavaglia, S., Moroz, V., 2002. Cross-industry, cross-country allocation. Financial Analysts Journal 58, 78-97.

Chen, J., Bennett, A., Zheng, T., 2006. Sector effects in developed vs. emerging markets. Financial Analysts Journal 62, 40-51.

Conover, C.M., Jensen, G.R., Johnson, R.R., Mercer, J.M., 2005. Is fed policy still relevant for investors? Financial Analysts Journal 61, 70-79.

Conover, C.M, Jensen, G.R., Johnson, R.R., Mercer, J.M., 2008. Sector rotation and monetary conditions. CFA Digest 38, 66-68.

Fama, E. F., Schwert, G.W., 1977. Asset returns and inflation. Journal of Financial Economics 5, 115-146. 
Ferreira, M.A., Gama, P.M., 2005. Have world, country, and industry risks changed over time? An investigation of the volatility of developed stock markets. Journal of Financial and Quantitative Analysis 40, 195-222.

Garcia, R., Perron, P., 1996. An analysis of the real interest rate under regime shifts. Review of Economics and Statistics 78, 111-125.

Gray, S.F., 1996. Modeling the conditional distribution of interest rates as a regime-switching process. Journal of Financial Economics 42, 27-62.

Griffin, J.M., Karolyi, G.A., 1998. Another look at the role of the industrial structure of markets for international diversification strategies. Journal of Financial Economics 50, 351373.

Grinold, R., Rudd, A., Stefek, D., 1989. Global factors: Fact or fiction? Journal of Portfolio Management 16, 79-88.

Guidolin, M., Timmermann, A., 2007. Asset allocation under multivariate regime switching. Journal of Economic Dynamics and Control 31, 3503-3544.

Guidolin, M., Timmermann, A., 2008. International asset allocation under regime switching, skew, and kurtosis preferences. Review of Financial Studies 21, 889-935.

Hamilton, J.D., 1989. A new approach to the economic analysis of nonstationary time series and the business cycle. Econometrica 57, 357-384.

Heston, S.L., Rouwenhorst, K.G., 1994. Does industrial structure explain the benefits of international diversification? Journal of Financial Economics 36, 3-27.

Heston, S.L., Rouwenhorst, K.G., 1995. Industry and country effects in international stock returns. Journal of Portfolio Management 21, 53.

Jaffe, J.F., Mandelker, G., 1976. The "Fisher effect" for risky assets: An empirical investigation. Journal of Finance 31, 447-458.

Longin, F., Solnik, B., 2001. Extreme correlation of international equity markets. Journal of Finance 56, 649-676.

Markowitz, H., 1952. Portfolio selection. Journal of Finance 7, 77-91.

Nelson, C.R., 1976. Inflation and rates of return on common stocks. Journal of Finance 31, 471-483.

Perez-Quiros, G., Timmermann, A., 2000. Firm size and cyclical variations in stock returns. Journal of Finance 55, 1229-1262.

Sassetti, P., Tani, M., 2006. Dynamic asset allocation using systematic sector rotation. Journal of Wealth Management 8, 59-70. 
Solnik, B.H., 1974. Why not diversify internationally rather than domestically? Financial Analysts Journal 30, 48-54.

Sorensen, E.H., Burke, T., 1986. Portfolio returns from active industry group rotation. Financial Analysts Journal 42, 43-50.

Stovall, S., 1996. Standard \& Poor's Guide to Sector Investing. McGraw-Hill Inc., US.

Turner, C.M., Startz, R., Nelson, C.R., 1989. A Markov model of heteroskedasticity, risk, and learning in the stock market. Journal of Financial Economics 25, 3-22.

Whitelaw, R.F., 2000. Stock market risk and return: An equilibrium approach. Review of Financial Studies 13, 521-547. 
Table 1: Composition of Regional Returns

\begin{tabular}{|c|c|c|c|c|}
\hline North America & UK Japan & Europe Large & Europe Small & Asia Pacific ex-Japan \\
\hline Canada & & Italy & Austria & Australia \\
\hline \multirow{9}{*}{ US } & & France & Belgium & Hong Kong \\
\hline & & Germany & Denmark & Singapore \\
\hline & & & Finland & New Zealand \\
\hline & & & Ireland & \\
\hline & & & Netherlands & \\
\hline & & & Norway & \\
\hline & & & Spain & \\
\hline & & & Sweden & \\
\hline & & & Switzerland & \\
\hline
\end{tabular}

The table lists the country composition of the geographic returns. Within each geographic region, we construct monthly returns, value-weighted in U.S. dollars.

Table 2: Descriptive Statistics - Regional Returns $1995 \sim 2010$

\begin{tabular}{lrrrrrrr}
$\begin{array}{l}\text { Sample } \\
\text { Moments }\end{array}$ & World & $\begin{array}{r}\text { North } \\
\text { America }\end{array}$ & UK & Japan & $\begin{array}{r}\text { Europe } \\
\text { Large }\end{array}$ & $\begin{array}{r}\text { Europe } \\
\text { Small }\end{array}$ & Pacific \\
\hline Mean & & & & & & & \\
Stdev & 0.18 & 0.36 & 0.12 & -0.32 & 0.38 & 0.60 & 0.26 \\
Skewness & 4.47 & 4.60 & 4.46 & 5.61 & 5.92 & 5.31 & 6.35 \\
Kurtosis & -0.87 & -0.77 & -0.53 & 0.15 & -0.63 & -0.77 & -0.53 \\
Beta & 1.90 & 1.26 & 2.15 & -0.19 & 1.73 & 1.72 & 2.03 \\
& & 0.98 & 0.88 & 0.84 & 1.18 & 1.09 & 1.15 \\
Correlation & & & & & & & \\
Matrix & World & America & UK & Japan & Large & Small & Pacific \\
\hline North America & 0.95 & & & & & & \\
UK & 0.88 & 0.79 & & & & & \\
Japan & 0.67 & 0.52 & 0.54 & & & & \\
Europe Large & 0.89 & 0.80 & 0.83 & 0.48 & & & \\
Europe Small & 0.92 & 0.82 & 0.87 & 0.56 & 0.94 & & \\
Pacific & 0.81 & 0.73 & 0.74 & 0.59 & 0.70 & 0.74 & \\
\hline
\end{tabular}

The table reports summary statistics for the regional returns. Regional returns and standard deviation are expressed as logarithmic price index returns at a monthly frequency in percentages. Regional returns are denominated in U.S. dollars and are from MSCI and are in excess of the U.S. 1-month T-bill return. The row labelled beta is the full-sample beta for each region's excess return with the world market excess return. The sample period for the regional returns is January 1995 to Mar 2010. 


\section{Table 3: Descriptive Statistics - Sector Returns 1995 2010}

\begin{tabular}{|c|c|c|c|c|c|c|c|c|c|c|c|}
\hline Sample Moments & World & Energy & Materials & Industrials & $\begin{array}{l}\text { Consumer } \\
\text { Discr }\end{array}$ & $\begin{array}{l}\text { Consumer } \\
\text { Staples }\end{array}$ & $\begin{array}{l}\text { Health } \\
\text { care }\end{array}$ & Financials & IT & Telecom & Utilities \\
\hline Mean & 0.18 & 0.59 & 0.26 & 0.14 & 0.12 & 0.31 & 0.41 & 0.05 & 0.62 & -0.04 & 0.09 \\
\hline Stdev & 4.47 & 5.08 & 5.48 & 4.78 & 5.02 & 3.35 & 3.81 & 5.71 & 7.96 & 5.42 & 3.42 \\
\hline Skewness & -0.87 & -0.18 & -0.66 & -0.89 & -0.39 & -0.70 & -0.49 & -0.62 & -0.30 & -0.06 & -0.95 \\
\hline Kurtosis & 1.90 & 0.86 & 2.63 & 2.76 & 1.51 & 1.41 & 0.32 & 2.77 & 0.75 & 2.28 & 1.25 \\
\hline Beta & & 0.72 & 0.99 & 0.98 & 0.99 & 0.46 & 0.50 & 1.12 & 1.43 & 0.84 & 0.48 \\
\hline
\end{tabular}

\begin{tabular}{|c|c|c|c|c|c|c|c|c|c|c|c|}
\hline $\begin{array}{l}\text { Correlation } \\
\text { Matrix } \\
\end{array}$ & World & Energy & Materials & Industrials & $\begin{array}{l}\text { Consumer } \\
\text { Discr }\end{array}$ & $\begin{array}{l}\text { Consumer } \\
\text { Staples }\end{array}$ & $\begin{array}{l}\text { Health } \\
\text { care }\end{array}$ & Financials & IT & Telecom & Utilities \\
\hline Energy & 0.62 & & & & & & & & & & \\
\hline Materials & 0.80 & 0.70 & & & & & & & & & \\
\hline Industrials & 0.93 & 0.61 & 0.85 & & & & & & & & \\
\hline Consumer Discr & 0.93 & 0.48 & 0.75 & 0.89 & & & & & & & \\
\hline Consumer Staples & 0.63 & 0.41 & 0.52 & 0.61 & 0.53 & & & & & & \\
\hline Healthcare & 0.61 & 0.35 & 0.39 & 0.52 & 0.47 & 0.69 & & & & & \\
\hline Financials & 0.89 & 0.50 & 0.71 & 0.86 & 0.82 & 0.68 & 0.60 & & & & \\
\hline IT & 0.84 & 0.41 & 0.56 & 0.72 & 0.80 & 0.29 & 0.38 & 0.60 & & & \\
\hline Telecom & 0.73 & 0.32 & 0.43 & 0.58 & 0.66 & 0.35 & 0.41 & 0.53 & 0.72 & & \\
\hline Utilities & 0.64 & 0.57 & 0.53 & 0.62 & 0.51 & 0.62 & 0.55 & 0.61 & 0.34 & 0.42 & \\
\hline
\end{tabular}

The table reports summary statistics for the sector returns. Sector returns and standard deviation are expressed as logarithmic price index returns at a monthly frequency in percentages. Sector returns are denominated in U.S. dollars and are from MSCI and are in excess of the U.S. 1-month T-bill return. The row labelled beta is the full-sample beta for each sector's excess return with the world market excess return. The sample period for the sector returns is Jan 1995 to Mar 2010. 
Table 4 Regime Switching Region Model In-Sample Estimates 1995 2002

A. Transitional probabilities

\begin{tabular}{lrr} 
Measure & P & Q \\
\hline Estimate & 0.98 & 0.97 \\
Std error & 0.07 & 0.07
\end{tabular}

B. World Market

\begin{tabular}{lrrrr} 
Measure & $\mu_{1}$ & $\mu_{2}$ & $\sigma_{1}$ & $\sigma_{2}$ \\
\hline Estimate & 0.98 & -0.14 & 2.26 & 4.92 \\
Std error & 0.35 & 0.55 & 0.32 & 0.62
\end{tabular}

C. Individual regions - Regime 1

\begin{tabular}{lrrrrrr} 
Region Betas & N Amer & UK & Japan & Eur lg & Eur sm & Pac \\
\hline Estimate & 0.84 & 0.69 & 1.68 & 0.75 & 0.67 & 1.03 \\
Std error & 0.12 & 0.14 & 0.27 & 0.16 & 0.13 & 0.20
\end{tabular}

\begin{tabular}{lrrrrrc} 
Region Alphas & N Amer & UK & Japan & Eur lg & Eur sm & Pac \\
\hline Estimate & 0.55 & 0.58 & -1.36 & 0.33 & 1.05 & -0.08 \\
Std error & 0.32 & 0.39 & 0.73 & 0.43 & 0.35 & 0.53
\end{tabular}

\begin{tabular}{lrrrrrr} 
Idiosyncratic Volatilities & N Amer & UK & Japan & Eur lg & Eur sm & Pac \\
\hline Estimate & 1.76 & 2.11 & 3.97 & 2.38 & 1.92 & 2.91 \\
Std error & 0.11 & 0.16 & 0.56 & 0.20 & 0.13 & 0.30
\end{tabular}

D. Individual regions - Regime 2

\begin{tabular}{lrrrrrr} 
Region Betas & N Amer & UK & Japan & Eur lg & Eur sm & Pac \\
\hline Estimate & 0.87 & 1.01 & 1.10 & 0.90 & 0.90 & 1.04 \\
Std error & 0.05 & 0.07 & 0.08 & 0.07 & 0.05 & 0.11 \\
& & & & & & \\
Region Alphas & N Amer & UK & Japan & Eur lg & Eur sm & Pac \\
\hline Estimate & 0.12 & 0.10 & -0.35 & 0.08 & 0.18 & 0.03 \\
Std error & 0.29 & 0.44 & 0.50 & 0.42 & 0.28 & 0.63 \\
& & & & & & \\
Idiosyncratic Volatilities & N Amer & UK & Japan & Eur lg & Eur sm & Pac \\
\hline Estimate & 2.82 & 4.46 & 4.70 & 4.28 & 2.86 & 5.91 \\
Std error & 0.28 & 0.43 & 0.49 & 0.41 & 0.28 & 0.62
\end{tabular}

All parameters are monthly and are expressed in percentages, except for the transitional probabilities $\mathrm{P}$ and $\mathrm{Q}$. 


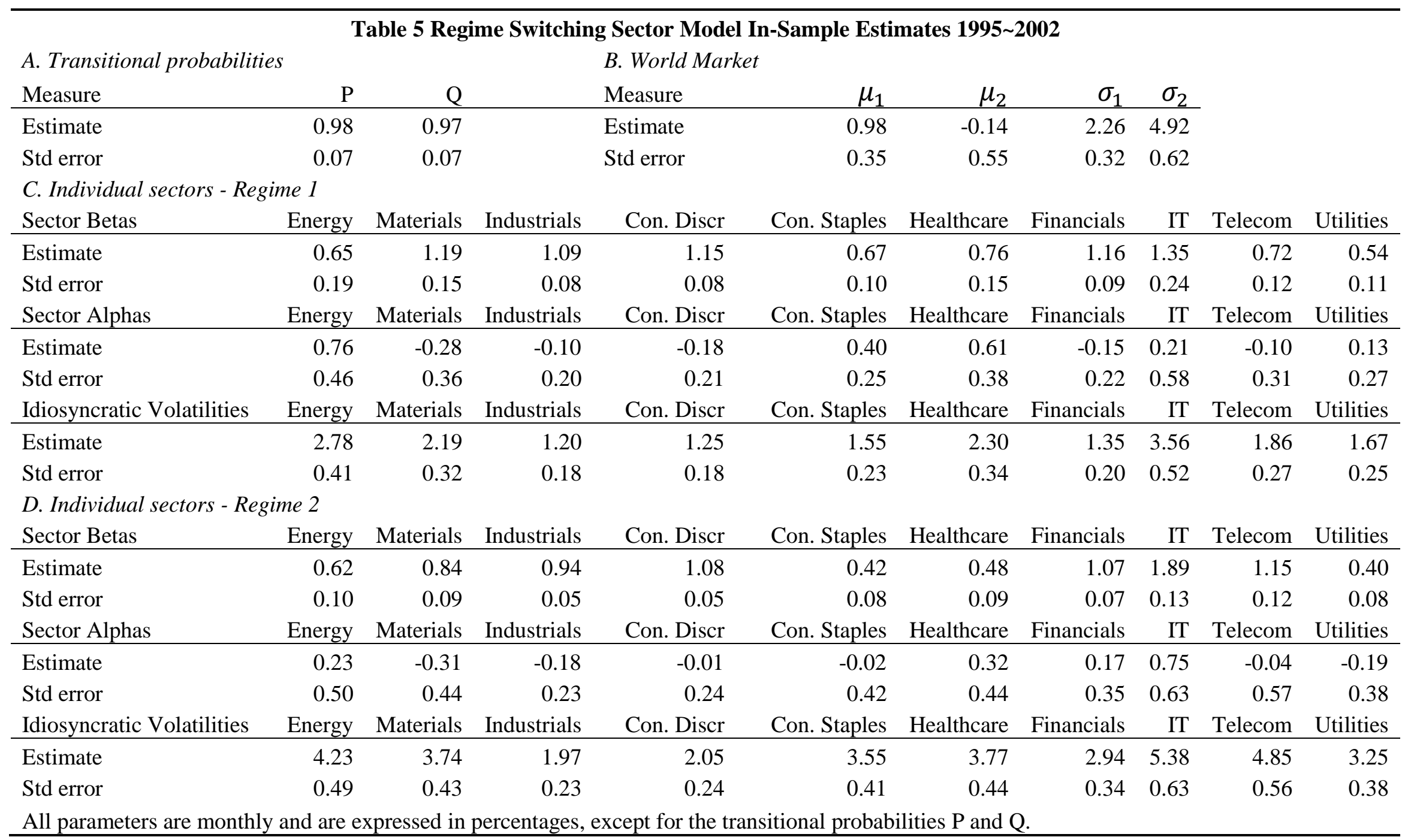


Table 6 Regime-Dependent Region Model Asset Allocation at January 2003

\begin{tabular}{|c|c|c|c|c|c|c|}
\hline & N Amer & UK & Japan & Eur lg & Eur sm & $\mathrm{Pac}$ \\
\hline \multicolumn{7}{|c|}{ A. Regime-dependent excess returns } \\
\hline Regime 1 & 16.17 & 14.75 & 2.81 & 12.44 & 20.20 & 10.69 \\
\hline Regime 2 & 0.26 & -0.23 & -5.75 & -0.31 & 0.89 & -1.10 \\
\hline \multicolumn{7}{|c|}{ B. Regime-dependent covariances and correlations } \\
\hline \multicolumn{7}{|l|}{ Regime 1} \\
\hline N Amer & 0.88 & 0.46 & 0.51 & 0.45 & 0.49 & 0.47 \\
\hline UK & 0.43 & 0.97 & 0.42 & 0.37 & 0.41 & 0.39 \\
\hline Japan & 0.93 & 0.79 & 3.71 & 0.41 & 0.44 & 0.43 \\
\hline Eur $\lg$ & 0.45 & 0.39 & 0.84 & 1.13 & 0.39 & 0.38 \\
\hline Eur sm & 0.41 & 0.36 & 0.76 & 0.38 & 0.80 & 0.41 \\
\hline $\mathrm{Pac}$ & 0.60 & 0.52 & 1.13 & 0.55 & 0.50 & 1.84 \\
\hline \multicolumn{7}{|l|}{ Regime 2} \\
\hline $\mathrm{N}$ Amer & 3.10 & 0.62 & 0.63 & 0.60 & 0.70 & 0.55 \\
\hline UK & 2.51 & 5.28 & 0.56 & 0.54 & 0.63 & 0.49 \\
\hline Japan & 2.74 & 3.18 & 6.11 & 0.54 & 0.63 & 0.49 \\
\hline Eur $\lg$ & 2.25 & 2.61 & 2.85 & 4.51 & 0.60 & 0.47 \\
\hline Eur sm & 2.24 & 2.61 & 2.84 & 2.33 & 3.29 & 0.55 \\
\hline $\mathrm{Pac}$ & 2.60 & 3.02 & 3.29 & 2.70 & 2.69 & 7.25 \\
\hline \multicolumn{7}{|c|}{ C. Tangency portfolio weights } \\
\hline MSCI Average & 0.50 & 0.09 & 0.22 & 0.08 & 0.07 & 0.06 \\
\hline \multicolumn{7}{|c|}{ C1. No constraints } \\
\hline Regime 1 & 0.46 & 0.28 & -0.25 & 0.04 & 0.53 & -0.06 \\
\hline Regime 2 & 0.88 & 0.04 & -0.53 & -0.06 & 0.75 & -0.08 \\
\hline Static & 0.48 & 0.15 & -0.06 & 0.03 & 0.50 & -0.10 \\
\hline \multicolumn{7}{|c|}{ C2. Short constraint } \\
\hline Regime 1 & 0.28 & 0.09 & 0.00 & 0.05 & 0.58 & 0.00 \\
\hline Regime 2 & 0.47 & 0.04 & 0.00 & 0.00 & 0.49 & 0.00 \\
\hline Static & 0.45 & 0.08 & 0.00 & 0.04 & 0.40 & 0.03 \\
\hline \multicolumn{7}{|c|}{ C3. Benchmark Constraint } \\
\hline Regime 1 & 0.41 & 0.09 & 0.12 & 0.18 & 0.17 & 0.06 \\
\hline Regime 2 & 0.60 & 0.19 & 0.12 & -0.03 & 0.17 & -0.04 \\
\hline Static & 0.56 & 0.08 & 0.12 & 0.12 & 0.17 & -0.04 \\
\hline
\end{tabular}

We report the regime-dependent means and covariances of excess returns implied by the estimates of the Regime-Switching Region Model in Table 4. Panel A and B report the regimedependent excess return means and covariances, where we list correlations in the upper-right triangular matrix. All numbers are listed in percentages, and are annualized. Panel $\mathrm{C}$ reports the mean variance efficient (MVE) (tangency) portfolios, computed using an interest rate of $4.55 \%$, which is the average 1-month T-bill rate over the sample. The MSCI Average denotes the average MSCI world index weight of each region across the sample. The short constraint requires weights to be positive, whereas the benchmark constraint does not allow the optimal region weights to deviate from their MSCI average weights by more than $10 \%$. 
Table 7 Regime-Dependent Sector Model Asset Allocation at January 2003

Energy Materials Industrials Con. Discr Con. Staples Healthcare Financials IT Telecom Utilities A. Regime-dependent excess returns

$\begin{array}{lrrrrrrrrrr}\text { Regime 1 } & 16.58 & 10.19 & 11.07 & 10.89 & 12.34 & 15.88 & 11.39 & 17.79 & 6.96 & 7.70 \\ \text { Regime 2 } & 1.83 & -5.00 & -3.51 & -1.67 & -0.86 & 3.09 & 0.53 & 6.23 & -2.13 & -2.85\end{array}$

B. Regime-dependent covariances and correlations Regime 1

\begin{tabular}{|c|c|c|c|c|c|c|c|c|c|c|}
\hline Energy & 1.19 & 0.45 & 0.46 & 0.41 & 0.22 & 0.22 & 0.26 & 0.20 & 0.38 & 0.44 \\
\hline Materials & 0.59 & 1.45 & 0.86 & 0.79 & 0.36 & 0.16 & 0.69 & 0.42 & 0.36 & 0.31 \\
\hline Industrials & 0.48 & 0.98 & 0.90 & 0.88 & 0.48 & 0.33 & 0.77 & 0.54 & 0.52 & 0.44 \\
\hline Consumer Discr & 0.45 & 0.95 & 0.84 & 1.00 & 0.60 & 0.39 & 0.75 & 0.54 & 0.52 & 0.44 \\
\hline Consumer Staples & 0.18 & 0.32 & 0.35 & 0.45 & 0.56 & 0.64 & 0.59 & 0.40 & 0.56 & 0.51 \\
\hline Healthcare & 0.24 & 0.20 & 0.31 & 0.39 & 0.48 & 0.99 & 0.52 & 0.37 & 0.54 & 0.36 \\
\hline Financials & 0.28 & 0.85 & 0.75 & 0.77 & 0.45 & 0.53 & 1.05 & 0.41 & 0.52 & 0.57 \\
\hline IT & 0.35 & 0.83 & 0.83 & 0.87 & 0.49 & 0.60 & 0.68 & 2.64 & 0.37 & 0.20 \\
\hline Telecom & 0.35 & 0.37 & 0.42 & 0.45 & 0.36 & 0.46 & 0.45 & 0.52 & 0.74 & 0.66 \\
\hline Utilities & 0.35 & 0.27 & 0.30 & 0.32 & 0.27 & 0.26 & 0.42 & 0.23 & 0.41 & 0.51 \\
\hline \multicolumn{11}{|l|}{ Regime 2} \\
\hline Energy & 3.27 & 0.65 & 0.62 & 0.47 & 0.41 & 0.36 & 0.58 & 0.37 & 0.25 & 0.52 \\
\hline Materials & 2.27 & 3.75 & 0.83 & 0.73 & 0.48 & 0.32 & 0.73 & 0.51 & 0.38 & 0.41 \\
\hline Industrials & 1.93 & 2.80 & 3.02 & 0.88 & 0.51 & 0.47 & 0.84 & 0.73 & 0.57 & 0.54 \\
\hline Consumer Discr & 1.69 & 2.79 & 3.01 & 3.88 & 0.39 & 0.38 & 0.78 & 0.82 & 0.70 & 0.41 \\
\hline Consumer Staples & 1.04 & 1.33 & 1.27 & 1.09 & 2.02 & 0.66 & 0.64 & 0.14 & 0.21 & 0.58 \\
\hline Healthcare & 1.00 & 0.95 & 1.26 & 1.17 & 1.45 & 2.38 & 0.58 & 0.28 & 0.35 & 0.50 \\
\hline Financials & 2.19 & 2.97 & 3.06 & 3.22 & 1.90 & 1.86 & 4.37 & 0.59 & 0.55 & 0.57 \\
\hline IT & 2.52 & 3.68 & 4.72 & 6.04 & 0.72 & 1.62 & 4.56 & 13.83 & 0.75 & 0.24 \\
\hline Telecom & 1.16 & 1.89 & 2.57 & 3.59 & 0.77 & 1.42 & 2.96 & 7.24 & 6.69 & 0.27 \\
\hline Utilities & 1.24 & 1.06 & 1.23 & 1.07 & 1.09 & 1.01 & 1.57 & 1.17 & 0.93 & 1.73 \\
\hline
\end{tabular}


C. Tangency portfolio weights

$\begin{array}{lcccccccrrr}\text { MSCI Average } & 0.09 & 0.06 & 0.10 & 0.11 & 0.09 & 0.10 & 0.22 & 0.12 & 0.06 & 0.04 \\ \begin{array}{l}\text { Cl. No constraints } \\ \text { Regime 1 }\end{array} & 0.24 & 0.02 & 0.33 & -0.26 & 0.49 & 0.27 & -0.15 & 0.05 & -0.30 & 0.30 \\ \text { Regime 2 } & 0.73 & -0.40 & -1.17 & 0.16 & 0.58 & 0.84 & 0.21 & 0.66 & -0.49 & -0.12 \\ \text { Static } & 0.49 & -0.12 & -0.50 & 0.30 & 0.41 & 0.56 & -0.19 & 0.21 & -0.18 & 0.03 \\ \text { C2. Short constraint } & & & & & & & & & & \\ \text { Regime 1 } & 0.29 & 0.00 & 0.00 & 0.00 & 0.41 & 0.18 & 0.00 & 0.04 & 0.00 & 0.09 \\ \text { Regime 2 } & 0.27 & 0.00 & 0.00 & 0.00 & 0.00 & 0.67 & 0.00 & 0.05 & 0.00 & 0.00 \\ \text { Static } & 0.32 & 0.00 & 0.00 & 0.00 & 0.14 & 0.51 & 0.00 & 0.04 & 0.00 & 0.00 \\ \text { C3. Benchmark Constraint } & & & & & & & & & & \\ \text { Regime 1 } & 0.19 & -0.04 & 0.16 & 0.01 & 0.19 & 0.20 & 0.12 & 0.07 & -0.04 & 0.14 \\ \text { Regime 2 } & 0.19 & -0.04 & 0.00 & 0.01 & 0.19 & 0.20 & 0.15 & 0.20 & -0.04 & 0.14 \\ \text { Static } & 0.19 & -0.04 & 0.00 & 0.14 & 0.19 & 0.20 & 0.12 & 0.10 & -0.04 & 0.14\end{array}$

We report the regime-dependent means and covariances of excess returns implied by the estimates of the Regime-Switching Sector Model in Table 4. Panel A and B report the regime-dependent excess return means and covariances, where we list correlations in the upper-right triangular matrix. All numbers are listed in percentages, and are annualized. Panel C reports the mean variance efficient (MVE) (tangency) portfolios, computed using an interest rate of $4.55 \%$, which is the average 1-month T-bill rate over the sample. The MSCI Average denotes the average MSCI world index weight of each sector across the sample. The short constraint requires weights to be positive, whereas the benchmark constraint does not allow the optimal sector weights to deviate from their MSCI average weights by more than $10 \%$. 
Table 8 Performance of Regional Allocation Portfolios

A. In-sample performance $1995 \sim 2002$

\begin{tabular}{lrrr} 
& \multicolumn{3}{c}{ No Constraints } \\
\cline { 2 - 4 } & World & Static & RS-Dynamic \\
Mean return $(\%)$ & 4.26 & 9.53 & 16.42 \\
Standard deviation $(\%)$ & 15.20 & 15.48 & 20.23 \\
Sharpe ratio & -0.02 & 0.32 & 0.59
\end{tabular}

\begin{tabular}{rrr}
\multicolumn{4}{c}{ Short Constraint } \\
\hline World & Static & RS-Dynamic \\
4.26 & 8.58 & 9.01 \\
15.20 & 15.79 & 15.89 \\
-0.02 & 0.26 & 0.28
\end{tabular}

\begin{tabular}{rrr}
\multicolumn{3}{c}{ Benchmark Constraint } \\
\hline World & Static & RS-Dynamic \\
4.26 & 7.08 & 6.02 \\
15.20 & 15.47 & 15.05 \\
-0.02 & 0.17 & 0.10
\end{tabular}

B. Out-of-sample performance $2003 \sim 2010$

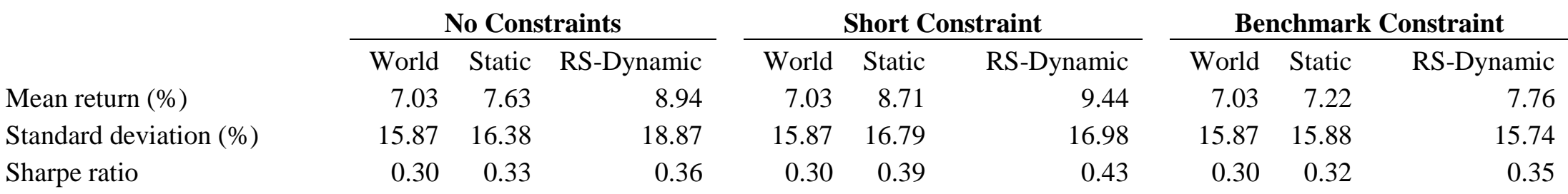

We present the mean, standard deviation and Sharpe ratio of both in-sample and out-of-sample returns following the Regime-Switching Region Model and a static non-regime dependent strategy. All returns are annualized and are reported in percentages. 
Table 9 Performance of Sector Allocation Portfolios

A. In-sample performance $1995 \sim 2002$

No Constraints

Mean return (\%)

Standard deviation (\%)

Sharpe ratio

\begin{tabular}{rc} 
& No Const \\
\hline World & Static \\
4.26 & 16.31 \\
15.20 & 13.90 \\
-0.02 & 0.85
\end{tabular}

RS-Dynamic

\begin{tabular}{rc}
\multicolumn{2}{c}{ Short Constr } \\
\hline World & Static \\
4.26 & 11.42 \\
15.20 & 12.60 \\
-0.02 & 0.55
\end{tabular}
18.13
19.43
0.70

$-0.02$

0.55

\begin{tabular}{rrr}
\multicolumn{3}{c}{ Short Constraint } \\
\hline World & Static & RS-Dynamic \\
7.03 & 6.61 & 7.82 \\
15.87 & 11.30 & 11.23 \\
0.30 & 0.39 & 0.50
\end{tabular}

\section{No Constraints}

\section{Mean return (\%)}

Standard deviation (\%)

Sharpe ratio

\begin{tabular}{rrr}
\multicolumn{3}{c}{ No Constraints } \\
\hline World & Static & RS-Dynamic \\
7.03 & 7.31 & 13.13 \\
15.87 & 10.65 & 11.74 \\
0.30 & 0.48 & 0.93
\end{tabular}

\section{straint}

RS-Dynamic

10.42
12.48
0.47

Benchmark Constraint World Static RS-Dynamic

$\begin{array}{lll}4.26 & 8.82 & 8.88\end{array}$

$\begin{array}{lll}15.20 & 12.64 & 13.38\end{array}$

$\begin{array}{lll}-0.02 & 0.34 & 0.33\end{array}$

We present the mean, standard deviation and Sharpe ratio of both in-sample and out-of-sample returns following the Regime-Switching Sector Model and a static non-regime dependent strategy. All returns are annualized and are reported in percentages. 


\begin{tabular}{|c|c|c|c|c|c|c|c|c|c|c|c|c|c|c|c|c|c|c|}
\hline \multicolumn{19}{|c|}{ Table 10 Comparison of Cross-Region and Cross-Sector Portfolios Performance $1995 \sim 2009$} \\
\hline \multirow[t]{2}{*}{ Year } & \multicolumn{2}{|c|}{ World } & \multicolumn{4}{|c|}{ Region-Static } & \multicolumn{4}{|c|}{ Region-RS } & \multicolumn{4}{|c|}{ Sector-Static } & \multicolumn{4}{|c|}{ Sector-RS } \\
\hline & Mean & Stdev & Mean & Stdev & Beta & SR & Mean & Stdev & Beta & SR & Mean & Stdev & Beta & SR & Mean & Stdev & Beta & SR \\
\hline \multicolumn{19}{|c|}{ A: In-sample period } \\
\hline 1995 & 1.46 & 2.51 & 2.32 & 1.98 & 0.65 & 3.24 & 3.13 & 2.54 & 0.18 & 3.63 & 2.80 & 1.63 & 0.39 & 5.00 & 2.32 & 2.01 & 0.33 & 3.18 \\
\hline 1996 & 0.95 & 2.35 & 1.56 & 2.07 & 0.72 & 1.89 & 2.49 & 2.67 & 0.52 & 2.67 & 2.61 & 3.08 & 1.21 & 2.46 & 2.15 & 2.44 & 0.83 & 2.44 \\
\hline 1997 & 1.18 & 4.10 & 2.53 & 3.71 & 0.88 & 1.97 & 4.15 & 4.39 & 0.77 & 2.95 & 3.32 & 5.19 & 0.93 & 1.94 & 2.61 & 4.47 & 0.88 & 1.70 \\
\hline 1998 & 1.87 & 5.64 & 2.36 & 5.73 & 0.99 & 1.18 & 3.52 & 6.59 & 0.98 & 1.64 & 2.67 & 5.10 & 0.64 & 1.54 & 4.43 & 7.76 & 0.81 & 1.80 \\
\hline 1999 & 1.83 & 3.50 & 1.57 & 3.30 & 0.91 & 1.25 & 0.35 & 4.84 & 1.04 & -0.02 & 0.04 & 4.15 & 0.32 & -0.28 & 0.03 & 7.78 & 0.34 & -0.16 \\
\hline 2000 & -1.17 & 4.15 & -0.78 & 4.14 & 0.96 & -1.05 & 0.22 & 4.75 & 0.87 & -0.19 & 1.25 & 3.71 & 0.19 & 0.72 & 2.28 & 6.14 & 0.53 & 1.01 \\
\hline 2001 & -1.49 & 5.24 & -1.46 & 5.19 & 0.98 & -1.17 & -0.60 & 7.09 & 1.28 & -0.44 & -0.45 & 2.72 & 0.35 & -0.96 & -0.56 & 4.71 & 0.53 & -0.64 \\
\hline 2002 & -1.80 & 5.56 & -1.76 & 6.20 & 1.11 & -1.06 & -2.32 & 9.16 & 1.54 & -0.93 & -1.35 & 4.03 & 0.49 & -1.27 & -1.22 & 5.75 & 0.59 & -0.81 \\
\hline Average & 0.35 & 4.40 & 0.79 & 4.48 & 0.97 & 0.32 & 1.37 & 5.86 & 1.07 & 0.59 & 1.36 & 4.07 & 0.54 & 0.85 & 1.50 & 5.61 & 0.63 & 0.70 \\
\hline \multicolumn{19}{|c|}{ B: Out-of-sample period } \\
\hline 2003 & 2.32 & 3.54 & 2.29 & 4.10 & 1.14 & 1.86 & 2.24 & 6.20 & 1.44 & 1.21 & 0.84 & 2.78 & 0.37 & 0.94 & 1.11 & 3.67 & 0.17 & 0.97 \\
\hline 2004 & 1.04 & 2.36 & 1.14 & 2.68 & 1.11 & 1.36 & 1.20 & 3.49 & 1.15 & 1.10 & 0.49 & 2.33 & 0.31 & 0.58 & 1.02 & 1.65 & 0.39 & 1.92 \\
\hline 2005 & 0.63 & 2.36 & 0.64 & 2.39 & 1.00 & 0.57 & 0.25 & 2.52 & 0.97 & 0.01 & 1.42 & 3.15 & 0.97 & 1.28 & 1.99 & 2.32 & 0.69 & 2.60 \\
\hline 2006 & 1.40 & 2.14 & 1.70 & 2.04 & 0.94 & 2.22 & 2.21 & 2.06 & 0.95 & 3.04 & 0.50 & 2.90 & 0.74 & 0.12 & 0.88 & 1.91 & 0.56 & 0.87 \\
\hline 2007 & 0.60 & 2.68 & 0.48 & 2.65 & 0.97 & 0.14 & 0.91 & 3.49 & 1.24 & 0.53 & 0.80 & 2.35 & 0.54 & 0.62 & 1.63 & 1.83 & 0.44 & 2.37 \\
\hline 2008 & -4.21 & 6.81 & -4.12 & 6.65 & 0.97 & -2.22 & -4.74 & 7.45 & 1.03 & -2.27 & -1.26 & 4.62 & 0.51 & -1.05 & -0.86 & 5.65 & 0.37 & -0.61 \\
\hline 2009 & 2.22 & 6.72 & 2.30 & 6.79 & 1.01 & 1.17 & 3.37 & 7.71 & 1.12 & 1.51 & 1.62 & 3.16 & 0.21 & 1.77 & 1.83 & 4.65 & 0.27 & 1.36 \\
\hline Average & 0.59 & 4.58 & 0.64 & 4.73 & 0.99 & 0.33 & 0.75 & 5.45 & 1.11 & 0.36 & 0.61 & 3.09 & 0.39 & 0.48 & 1.09 & 3.37 & 0.34 & 0.93 \\
\hline
\end{tabular}

We compare the mean, standard deviation, beta and alpha generated from static and regime switching regional allocations against their counterparts in the sectoral allocations. All returns and standard deviations are reported monthly and are reported in percentages. 
Figure 1 Ex Ante and Smoothed Regime Probabilities of Being in (the Normal) Regime 1: 1995 2010

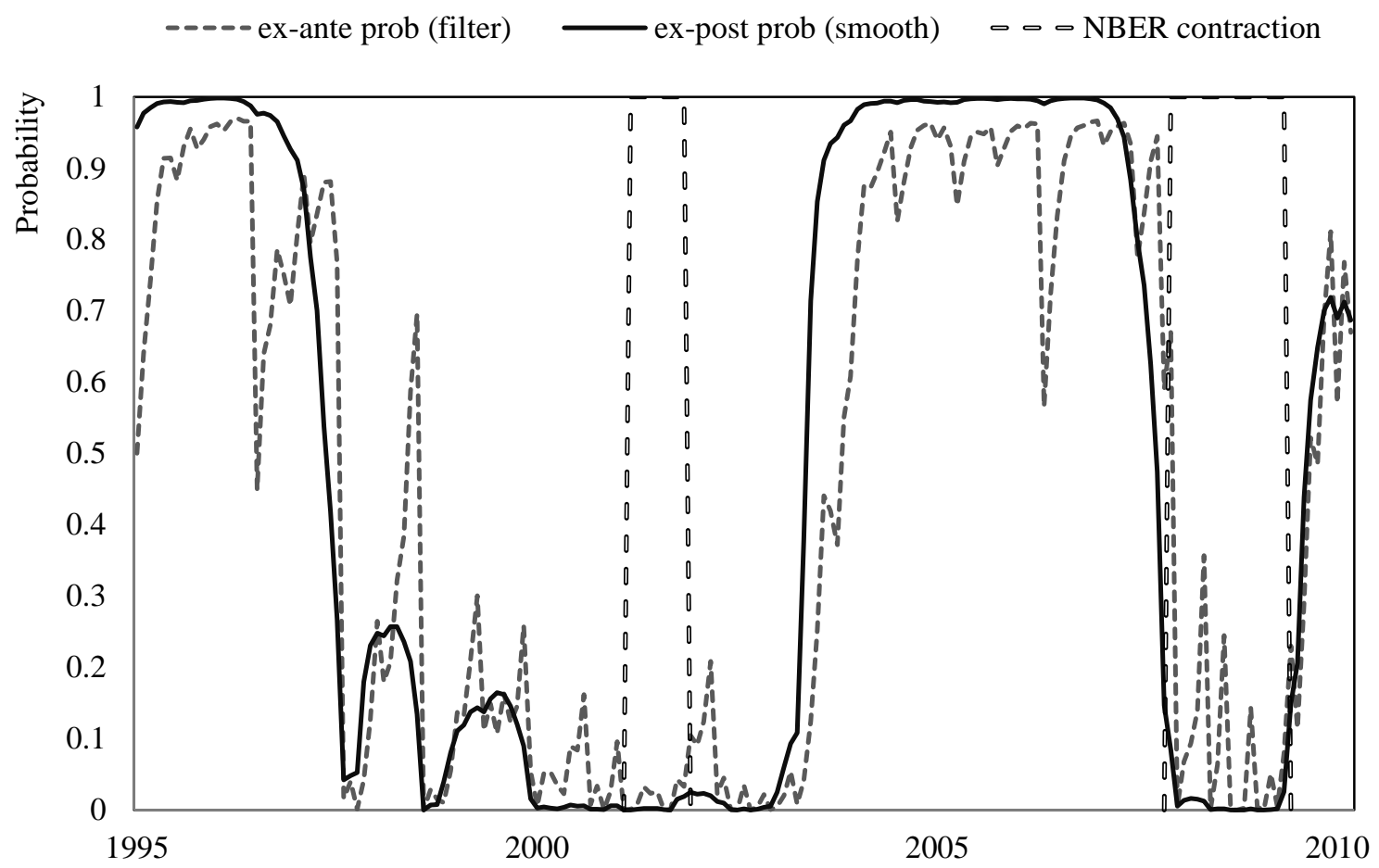

The plot shows the ex ante probabilities $p\left(s_{t}=1 \mid I_{t-1}\right)$ and the smoothed probabilities $p\left(s_{t}=1 \mid I_{T}\right)$ of being in the first regime, where the first regime is the world low variance regime. 
Figure 2 In and Out of Sample Wealth for the Regional Allocation Model - No Constraints

A. In Sample Regional Allocation Model 1995 2002

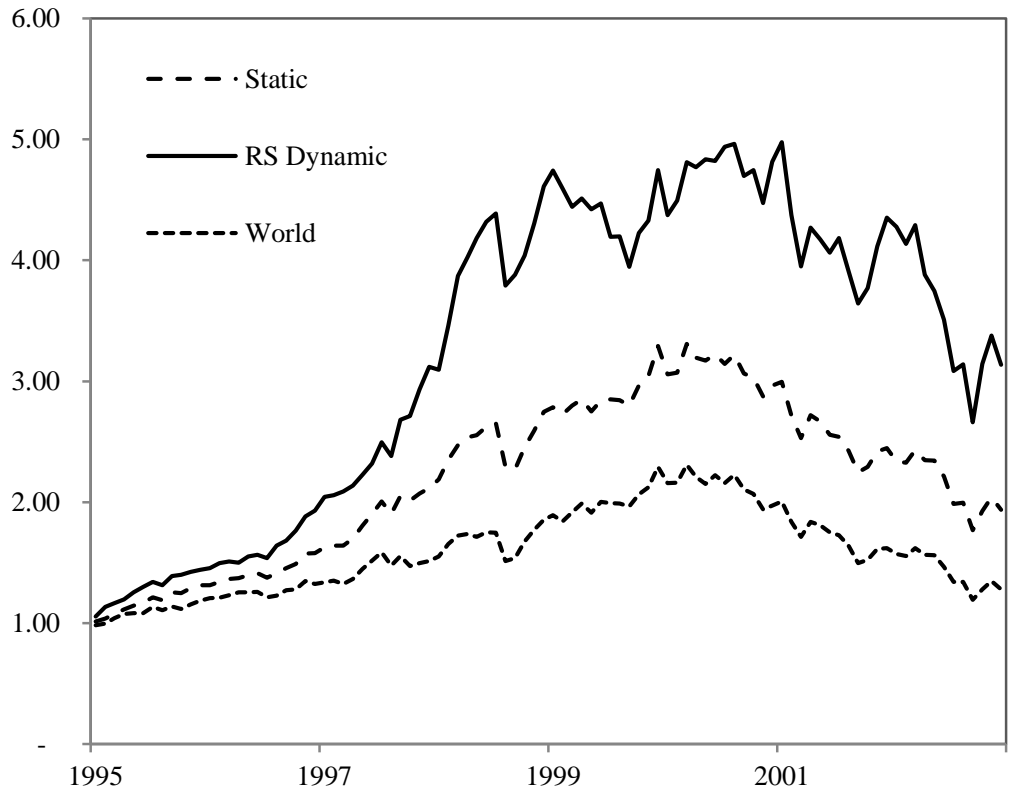

B. Out of Sample Regional Allocation Model 2003 2010

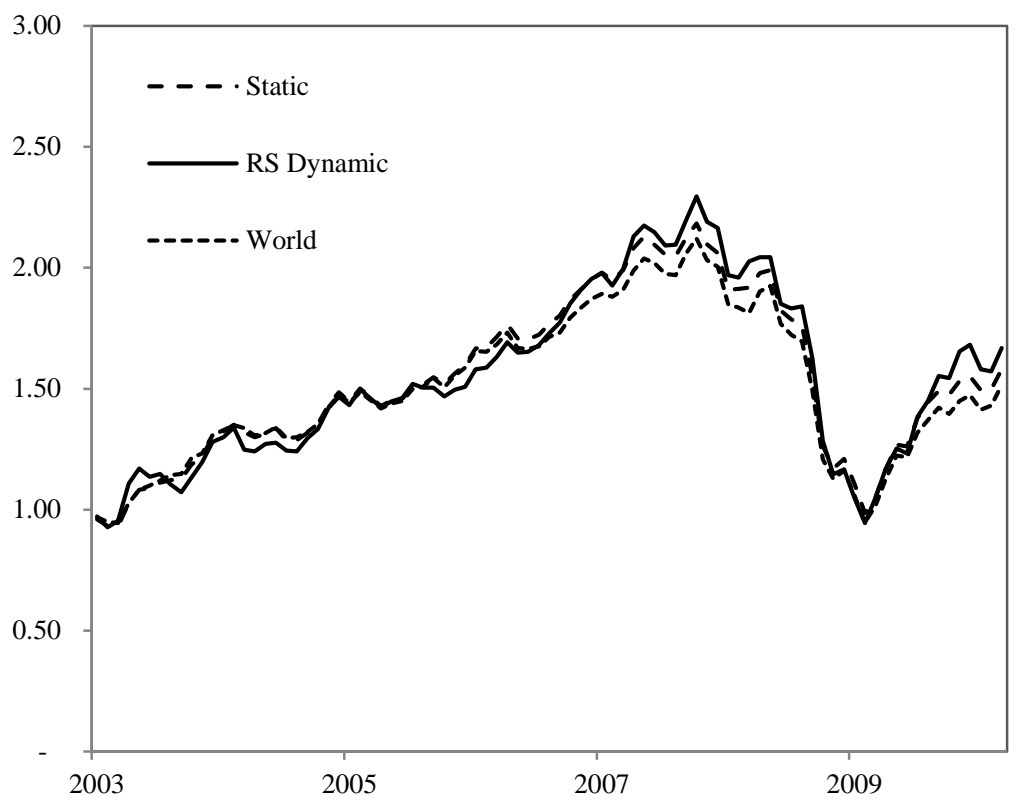

The top plot shows the in-sample wealth for the value of $\$ 1$ at January 1995 for the RegimeSwitching Regional Allocation Model with no constraint, contrasted with a static mean-variance strategy, and the returns for the world portfolio. The bottom plot shows the out of sample wealth for the value of \$1 at Jan 2003 for the Regime-Switching Regional Allocation Model with no constraint. 
Figure 3 In and Out of Sample Wealth for the Sector Allocation Model - No Constraints

A. In Sample Sector Allocation Model 1995 2002

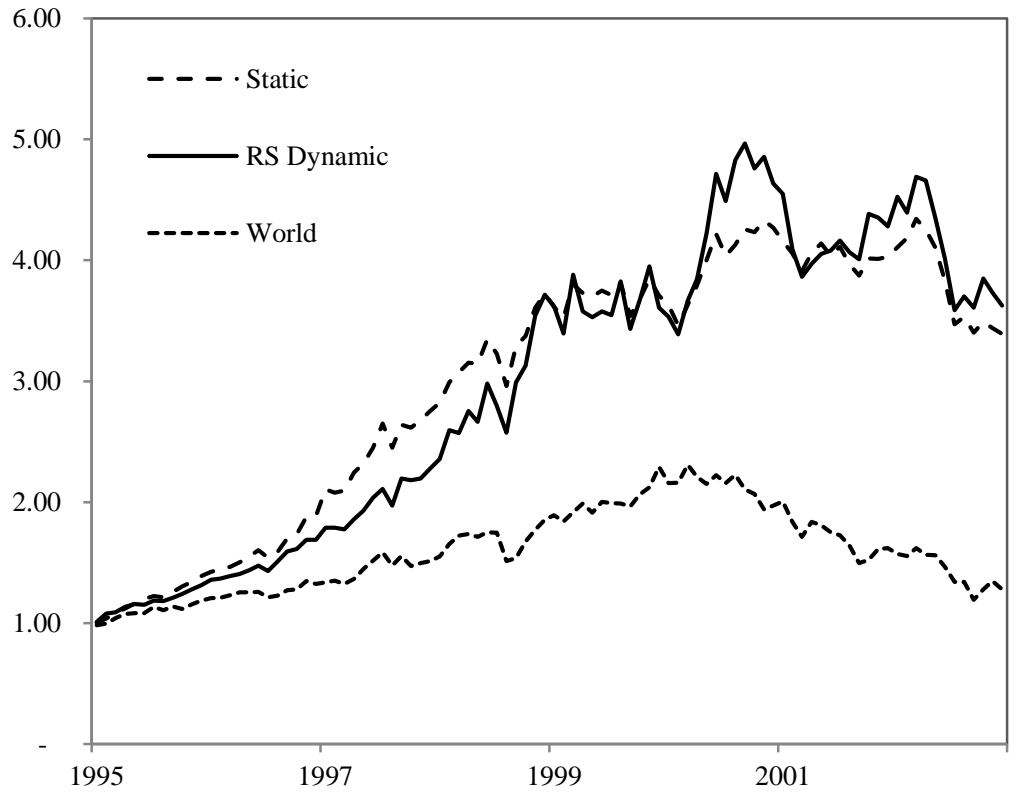

B. Out of Sample Sector Allocation Model 2003 2010

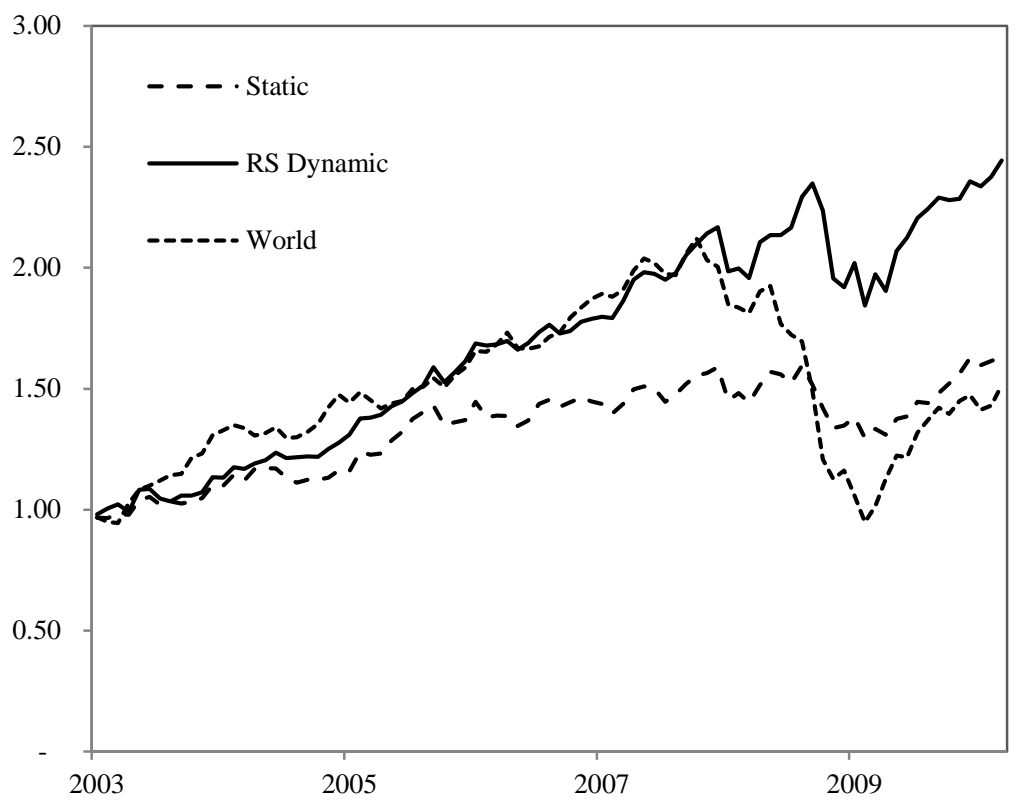

The top plot shows the in-sample wealth for the value of $\$ 1$ at January 1995 for the RegimeSwitching Sector Allocation Model with no constraint, contrasted with a static mean-variance strategy, and the returns for the world portfolio. The bottom plot shows the out of sample wealth for the value of \$1 at January 2003 for the Regime-Switching Sector Allocation Model with no constraint. 